\title{
Prevention of Tobacco Use in Youth with Disabilities: A Video Experimental Model
}

\author{
Denise M. Green*, Heather Lewis, Sara Vogt \\ College of Health and Human Services, Troy University, 153 A Collegeview Bld., Troy, Alabama, USA.
}

Article Detaills
Article Type: Research Article
Received date: $27^{\text {th }}$ August, 2020
Accepted date: $06^{\text {th }}$ September, 2020
Published date: $08^{\text {th }}$ October, 2020
*Corresponding Author: Dr. Denise Marcella Green, College of Health and Human Services, Troy University, 153 A Collegeview
Bld., Troy, Alabama, USA.. E-mail: $\underline{\text { dmgreen@troy.edu }}$
Citation: Green, D.M., Lewis, H., \& Vogt, S. (2020). Prevention of Tobacco Use with Youth with Disabilities: A Video Ex-
perimental Model. J Pub Health Issue Pract 4(2):168. doi: https://doi.org/10.33790/jphip1100168.
Copyright: C2020, This is an open-access article distributed under the terms of the Creative Commons Attribution License
4.0, which permits unrestricted use, distribution, and reproduction in any medium, provided the original author and source are
credited.

\begin{abstract}
This article reviews literature available in relationship to youth tobacco prevention through education and use of a video creation by the students. The study also incorporates the Cone of Experience in relationship to the students retaining knowledge from the process of creating short video clips related to the effects of tobacco use in youth. Data for this study was collected via pre- and post-test questionnaires of youth students attending a Boys \& Girls Club of America in Southeastern United States. Various descriptive statistical analyses were utilized to compare the results of the pre- and post-tests to determine how much students learned from educational presentations and video creation in relationship to tobacco prevention.
\end{abstract}

Keywords: Tobacco Prevention, Youth with Disabilities, Cone of Experience, Video Experimental Model, Risk taking Behavior

\section{Introduction}

Many research efforts have been presented in relationship to adolescents with learning disabilities who misuse drugs and abuse illegal substances. There is a lack of research available that details the misuse of tobacco products by youth and adolescents that suffer from learning and mental disabilities. In this study, the Cone of Experience was utilized as a method for educating adolescents on the risks and complications of using tobacco related products.

Previous research has indicated that at-risk populations are more at risk for increased tobacco use [1, 2]. Factors attributing to at-risk populations include those of minorities, lower socioeconomic status, lack of education, and participation from parents. Additionally, there is a known connection between tobacco and substance abuse with adolescents with learning disabilities [3-5]. Edgar Dale's [6] Cone of Experience is of importance to this study because it has been proven through previous research to assist in the retention of information presented through audio and visual materials. Moreover, those who participate in experiential activities are known to retain even more of the knowledge gained according to the Cone of Experience [6]. After reviewing the previous literature and research available, a research gap presented itself. This research effort intended to reach at-risk adolescent populations, many of which are likely to have learning disabilities, by utilizing experiential educational presentations and projects to inform them about tobacco products and the risks associated.

The data for this study was collected at a Southeast Alabama Boys J Pub Health Issue Pract Volume 4. 2020. 168 and Girls Club of America (BGCA). Unfortunately, the state of Alabama is recognized as not having favorable rankings in relationship to tobacco usage. As of 2017, the national rate of tobacco usage in adults was $17.1 \%$ but $20.9 \%$ for Alabama. In a 2015 study of high school students, they indicated participation in the following activities at least once in the last 30 days: $14 \%$ of high school students in Alabama smoked cigarettes compared to the national average of $10.8 \% ; 24.5 \%$ used e-cigarettes or vapor products while the national average was $24.1 \%$; and $12.5 \%$ of Alabama students reported using chewing tobacco, snuff, or dip while the national average was only $7.3 \%$ [7]. These statistics prove that adolescents residing in Alabama are more likely to participate in the usage of tobacco related products in comparison to adolescents nationwide. It also indicates that there is a need for preventative educational measures to be implemented within at-risk populated areas in Southeast Alabama territories.

The primary purpose of this study was to examine likelihood of adolescents to use tobacco products, which serves as a gateway substance to alcohol and illegal drugs, following an educational seminar. In the following sections of this paper, a thorough literature review details the significance of educating adolescents on the dangers of tobacco use and the statistical relevance of tobacco use associated to adolescents with learning disabilities. Within the methodology and results sections, the data collection, analysis, and findings of this study will be discussed in detail. Additional information relative to limitations and future research opportunities will conclude this research manuscript.

\section{Literature Review}

There are numerous research studies available in relation to substance use by adolescents with learning disabilities [2-5, 8-12]. Per the University of Maryland Medical Center [13] substance use is the ongoing utilization of liquor, drugs, or the abuse of a drugs prescribed by a physician, or drugs sold directly to a consumer without a prescription with harmful results. For purposes of this research paper, tobacco products are also going to be considered as a substance. Tobacco and alcohol use have played a significant role in the declining health of the general population, as well as paving a path for substance addiction later in life [4].

There are many factors that could lead to addiction of substances in youth: learning disabilities, depression and violence [12], psychological disorders and poverty levels [4], chemical dependency, race, socioeconomic status, age, and gender [2].

JPHIP, an open access journal ISSN- 2581-7264 
Adolescents with learning disabilities tend to partake in substances frequently as an outcome of their surroundings. Some of those factors are due to trying to handle their problems or conducting themselves better in school, peer pressure, types of abuse, others in the home using drugs, hereditary genetic vulnerability, intellectual disorders, and the availability of drugs [14]. The CDC also recognized lower pay or schooling, lack of talent to endure authority to utilizing tobacco, lack of assistance or participation from parents, the cost of tobacco products, little self-regard, and exposure to tobacco advertising to be factors increasing tobacco use [1]. Partaking in the use of substances leads to risky behaviors and maybe even criminal acts.

\section{Learning Disabilities and Substance Abuse}

The Center for Disease Control and Prevention (CDC) described youth with a learning disability as an adolescent struggling in one or more of their academic studies and their standard intellect is not learning disabilities and substance abuse over the years. It has been found that as much as $70 \%$ of chemically dependent adolescents have also been diagnosed with a learning disability [12].

Beitchman, et al. [3] completed a two-part research study to determine if youth between the ages of 12-19 had learning disabilities and then were reassessed after they turned nineteen years of age to determine if they had any substance abuse disorders. It was determined from Beitchman, et al.'s [3] study that participants with a learning disability were more likely to develop a substance abuse disorder or a psychiatric disorder compared to those students without a learning disorder. Those with a learning disability were found to be three-times more likely to be at risk of substance use disorders when behavioral issues and family history were also factored into the data [3]. This study was comprised of primarily Caucasian participants presenting a need for this study to be replicated on a more diverse population.

Another study that focused heavily on connections between substance use and substance abuse with youth having learning disabilities, specifically Attention Deficit Hyperactivity Disorder (ADHD), was published by Molina and Pelham [5]. They surveyed a group of youth enrolled in a summer treatment program for youth with ADHD and discovered that adolescents with just a learning disability were less and not both likely to drink heavily but were more likely to have tried cigarettes [5]. The participants with ADHD who had higher IQs and higher levels of academic achievement were found to be more likely to try cigarettes, smoke daily, and try their first cigarette or alcoholic drink at an earlier age [5].

In a study completed by Emerson and Turnbull [4], it was determined that the prevalence of alcoholism is lower among youth with intellectual disabilities. Alternatively, in the same study by [4] it was also found that youth with mild intellectual disabilities have higher rates of both smoking and alcohol use. Children with intellectual disabilities in this research effort also reported being a current smoker at higher rates than that of non-intellectually disabled children [4].

One specific research study was completed with the intention of determining whether substance abuse treatment would be less effective for patients suffering from a learning disability [12]. This study compared substance abuse treatment outcomes between young people with and without learning disabilities in Massachusetts. It was determined by this research study that those suffering from learning disabilities had higher rates of adverse post-treatment outcomes, such as incarceration rate and substance re-use [12].

\section{Cone of Experience}

For this research study, Edgar Dale's Cone of Experience will serve as the theoretical framework to help us determine the success of our educational presentations and activities in relation to tobacco prevention. Edgar Dale regarded his Cone of Experience as a tool to altered [1]. Many researchers have investigated connections between

show progression of concrete to abstract learning experiences [15]. The Cone of Experience theory references that if you experience something either by reading, hearing, seeing, saying, doing or combination of those acts, then you will retain information by greater percentages based on the activity associated [6]. Dale incorporated the influences of Bruner's [16] modes of learning into his Cone of Experience, which categorized the layers of activity in the Cone into three modes: enactive (i.e. learning by doing), iconic (i.e. learning by observation), and symbolic experience (i.e. learning by abstraction). Ultimately, it is theorized that learners will retain more information by doing than sampling hearing, reading, or observing - this is most commonly recognized as experiential learning [17].

Within the Cone of Experience, there are six primary levels to consider and within each of those levels there are different ways of presenting information to individuals. Percentages of retention are associated to each of the six levels of activities. Within the top peak of the Cone, is reading. If you read something, you are said to retain approximately $10 \%$ of the information according to Dale's Cone of Experience [17]. This area of the cone is directly connected with hearing information presented and accounts for approximately $20 \%$ of retention. Reading would be considered a symbolic experience, while listening would be an iconic experience if utilizing Bruner's [16] modes of learning. The desired learning outcomes for someone who has either read or listened to information presented on a topic that they be able to define, describe, list, or explain what was just experienced [17].

The second tier of the Cone accounts for watching still or moving pictures, viewing exhibits, or watching demonstrations. In watching still or moving pictures, $30 \%$ retention is expected from seeing something. Participants will likely retain $50 \%$ of information that is viewed as an exhibit or demonstration as they've experienced a combination of seeing and hearing the information presented [6]. Demonstrating, applying, and practicing are the desired learning outcomes within this tier [17]. It is within the top two sectors of the Cone that learners are considered to be passive learners [6]. All of these areas would fall into iconic experiences if utilizing Dale's [6] adaptation of modes of learning from Bruner [16].

Finally, within the third tier of the Cone, participants would be experiencing information by participation in hands-on workshops, role-playing situations, simulation of real experiences, or direct purposeful experiences. It is within this bottom tier of the cone that the majority of information is retained by either a combination of saying and writing ( $70 \%$ retention rate) or by doing a task $(90 \%$ retention) [17]. All of these enactive activities [16] lead to projected learning outcomes of analyzing, designing, creating, and evaluating [17].

By utilizing Edgar Dale's [6] Cone of Experience theory as the framework for this study, the researchers' developed an educational seminar related to the risks and complications of using tobacco related products for adolescents. By developing educational activities based on the Cone of Experience, the researchers intend to report on the student retention of the information presented to them through the experiential learning activities. According to Dale's [6] Cone of Experience, students should retain approximately thirty-percent of what they saw and heard in the presentation.

Also, within the seminar, students participated in the creation of a video commercial focused on the prevention of youth tobacco usage. This would allude to the students retaining roughly ninetypercent of the information they learned through their efforts of both saying and doing the activity themselves according to the Cone of Experience [6]. By using audiovisual materials, it is proposed that those materials will "provide a concrete basis for learning concepts, heighten students' motivation, encourage active participation, give needed reinforcement, widen student experiences, and improve the effectiveness of other materials" [15].

J Pub Health Issue Pract

Volume 4. 2020. 168
JPHIP, an open access journal ISSN- 2581-7264 
Therefore, based on previous research and the Cone of Experience [18] model, the study's aim is threefold: (1) examine participants' retention of information, (2) examine altered perceptions of participants, and (3) examine participants' change of anticipated behavior as related to tobacco products following an educational seminar.

\section{Methodology \\ Population and Sample}

The purpose of this study was to examine the likelihood of adolescents to consume tobacco products subsequent to an educational seminar on the risks and complications of using tobacco related products. Therefore, the target population for this study was adolescent children under 18 years of age because they are more likely to be exposed to peer pressures related to trying tobacco products, alcohol, or other drugs [19]. Boys and Girls Clubs of America (BGCA) serve youth ages 6-18 and are focused towards providing educational and youth development opportunities to low income children and adolescent populations [20]. In many situations these children are considered at-risk populations due to the BGCA club placements being located primarily in low-income, minority populated areas. Within their programing they strive to "empower kids to lead healthy and productive lives with life-enhancing programs" [21].

As the purpose of this study directly aligned with the mission of the BGCA, the researcher obtained the final sample for this study from a small-town Southeastern Alabama Boys and Girls Club. The advantage to this sampling method is that all data was collected within the same club, providing the ability to control for variables such as geographical region, socioeconomic status, and the environment of the small-town controls for similar exposure to tobacco advertisements for the respondents. Therefore, a purposive sampling method was employed to obtain responses from adolescents between the ages of 6-17 from a Southeastern Alabama Boys and Girls Club.

\section{Instrument}

The primary objective of the current study was to examine the intended tobacco related behaviors of adolescents following an educational seminar. Therefore, the researchers utilized the recommendations of [22] in development of an instrument. First, a thorough review of relevant literature and theoretical frameworks were utilized to specify and define various constructs. Next, a deductive approach was applied to produce the necessary items of the instrument. Finally, a panel of experts evaluated the content validity of the instrument. Two scholars were asked to conduct a content analysis, while two practitioners were asked to assess the face validity. Overall, the review of the content relevance, readability, and clarity of the content was adjusted based on the recommendations of the panel to provide the final instrument for the study.

The pre-test asked a set of four questions related to demographics. Specifically, those questions asked their age, gender, academic grade, and race or ethnic grouping. This information was utilized to provide a demographic profile of the respondents. Eight questions focused on their awareness and perception of tobacco products and health complications caused by using tobacco products. The responses within these questions were used to gain a better understanding of the respondents' retention and perception. Two additional questions on the survey inquired about the students' prior use of tobacco products and their intent to use in the future. These responses were utilized to examine the likelihood of change in the expected behaviors of the respondents.

\section{Data Collection}

A request to the Institutional Review Board (IRB) to conduct this study was submitted and approved. The students who participated in the study were granted parental permission prior to them taking the survey and participation in the activities affiliated to the research study. To properly evaluate the intervention program and achieve J Pub Health Issue Pract Volume 4. 2020. 168 the overarching purpose of this study, it was necessary to employ a pre- and post-test. Therefore, at the beginning of the educational seminar the participants were given the pre-test. The intention of the pre-test was to gain a baseline knowledge level of the students in regard to their educational awareness of tobacco related products. The entire survey consisted of fourteen questions and took the group of participants roughly 15-20 minutes to complete each time it was taken.

After the students completed the pre-survey, the same set of students were involved in an educational presentation on tobacco products and the health complications as a result of using tobacco related products. This consisted of a PowerPoint presentation and open dialog with students allowing them time to ask questions and become more knowledgeable about tobacco awareness and use prevention. Next, the group was tasked with creating an educational video commercial on tobacco awareness and prevention. At the conclusion of the presentation and their participation in creating the video commercial for tobacco awareness, the students then completed the same survey again in the form of a post-survey. The post-test served as a gauge for comparison to see how much the students learned throughout the educational presentation and their participation in the video commercial creation.

\section{Data Analysis}

The data was analyzed and processed using SPSS Statistics 25 software. Based on the purpose of this study, a combination of descriptive statistical analyses was examined to provide a clear foundation of knowledge for practical application and future research. Descriptive statistics were used to create a demographic profile of the participants. To address the retention of information, change in perceptions, and anticipated behaviors of the respondents means were compared to adequately analyze the participants' preand post-test responses.

\section{Results}

There was a total of 32 participants that took both the pre- and posttests and completed the two activities associated with the research study. The age of students who participated in the study ranged from 9 to 17 years of age, with the majority of participants being 9 years of age (36\%) with 11-years of age being the next largest group (23\%). Females $(47 \%)$ represented the bulk of the participants; while the majority of the sample was reportedly in the 6th grade $(23 \%)$. Additionally, $89 \%$ of respondents listed their race or ethnicity as being black or African American.

\section{Retention}

The BGCA students were asked what problems resulted from smoking tobacco products with the options for response being heart disease, cancer, stroke, asthma, and all of the above. Results showed that $40.6 \%$ of BGCA students who participated in the study realized that all of the choices listed were potential health problems as a result of using tobacco products in the pre-test $(\mathrm{M}=3.18)$, but $45.2 \%$ knew that all of the choices were potential health problems when taking the post-test $(\mathrm{M}=3.61)$. This indicates that our activities did increase the knowledge level of $4.6 \%$ of the students in regard to the potential health risks involved in partaking in tobacco related products.

A similar question was asked in regard to potential reactions of using tobacco related products. The students were given choices of yellow teeth, smelly clothes and hair, loss of taste and/or smell, trouble breathing while exercising, and all of the above. Pre-test results showed that $37.5 \%$ of the students believed that all of the above listed items were potential reactions caused by smoking tobacco products $(\mathrm{M}=3.18)$, while post-test results showed that $46.7 \%$ understood that all of those issues would result from smoking tobacco products $(\mathrm{M}=3.83)$. This showed an overall increase of $9.2 \%$ of the BGCA students recognizing the potential reactions of smoking tobacco products. 
Based on the results of the pre- and post-test results from the BGCA study participants, it can be concluded that students will retain information as it relates to the dangers of tobacco products and usage through the use of experiential learning activities. It is clear that utilizing educational activities from different levels of the Dale's [6] Cone of Experience in relationship to the dangers of utilizing tobacco products did improve the knowledge retention rate of the BGCA students at this particular location.

\section{Perception}

In comparing the pre- and post-test data results, it was clear that participants' perception of the dangers and consequences of using tobacco products changed as a result of participating in experiential learning activities was supported by this research study. The experiential learning activities that the BGCA student sample participated in did change their perception of the dangers and consequences of using tobacco related products. In the pre-test results, when students were asked "Do you believe e-cigarettes are harmful?" 58.1\% said "yes," $16.1 \%$ said, "no" and $25.8 \%$ answered "I don't know" (M=1.67). After participating in our lecture and experiential learning activities, students responded to the same question in the post-test. The results in the post-test yielded a 76.7\% response rate for "yes," $20 \%$ said, "no" and only $3.3 \%$ said "I don't know" ( $M=1.26)$. Overall, utilizing the descriptive statistics for the question, "Do you believe e-cigarettes are harmful?" shows an 18.6\% increased rate of change. This specific question was of importance to us because teens in the United States are more likely to use e-cigarette products in comparison to traditional cigarettes [23]. To further the importance of education in regard to dangers of using e-cigarettes, teens who use e-cigarettes are more likely to transition to the use traditional cigarettes [23].

The next question asked of the BGCA students was, "Do you believe smoking leads to the use of drugs or alcohol?" Pre-test results of this question showed $59.4 \%$ of students said "yes" $12.5 \%$, said "no", and $28.1 \%$ were not sure and responded, "I don't know" (M=1.68). Post-test results showed that $68.8 \%$ of students learned from the educational presentations and experiential learning activities that "yes" smoking tobacco products does lead to the use of other drugs and/or alcohol products. $12.5 \%$ still responded with "no" to the same question and $18.8 \%$ were still unsure and responded, "I don't know" $(\mathrm{M}=1.50)$. This indicates an increase of $9.4 \%$ of students recognizing that smoking tobacco related products can lead to the use of other drugs and alcohol products as a result of our educational presentation and experiential learning activities.

The final question asked of the participants in relationship to change of perception, was "How strongly do you agree with the statement, "All tobacco products are dangerous?". Pre-test results indicated that $71 \%$ of participants said they either agreed or strongly agreed that tobacco products were dangerous $(\mathrm{M}=1.80)$. In the post-test results, the percentage associated to either agree or strongly agree increased to $90.3 \%(\mathrm{M}=1.45)$. Overall, this was a significant improvement in regard to changing the adolescents' perception of the dangers related to tobacco products.

\section{Behavior}

The third hypothesis statement: "students will be less likely to use tobacco related products after participating in the experiential learning activities of this study" was also supported by this research study. BGCA students that participated in our experiential learning activities were asked the question in both the pre- and post-test, "Do you intend to use any tobacco products in the future?" Pre-test results showed that $78.1 \%$ of participants said "no" they would not use tobacco products, while $21.9 \%$ said "I don't know" $(\mathrm{M}=2.21)$. After participating in the different experiential learning activities, posttest results indicated that the percentage of students who said "no" increased to $85.7 \%(\mathrm{M}=2.14)$, showing a $7.6 \%$ change in likelihood to not use tobacco related products.

\section{Discussion}

Knowledge retention through experiential educational activities, altering the perception of risk, and anticipating the behaviors of adolescents in relationship to tobacco related products were the generalized objectives of this research effort. This research study utilized Dale's [6] Cone of Experience model in combination with experiential learning activities to educate students attending a local BGCA about tobacco related products and risks of usage. Additionally, this research effort was developed to decrease the likelihood of adolescent participants to partake in the usage of tobacco related products preventing them from becoming a gateway substance to alcohol and illegal drugs.

Results of the study provided that using the Cone of Experience to educate students on the health risks and potential ramifications of using tobacco products did aid in the retention of information presented to the students. Dale's [6] Cone of Experience illustrates the importance of effective communication and learning for younger populations to provide a foundation for permanent learning on a topic. This research showed through improved responses on the post-test that they did retain information presented and have a better understanding of the complications and risks associated with using tobacco related problems.

This research study also indicated that as a result of the educational presentations, students' perception of danger and risk associated with tobacco products drastically changed from the pre- and posttest results. Students had a better understanding of risk associated to using tobacco related products after our educational presentation and activities in comparison to what they knew beforehand. It can be assumed that students entering into the experiential learning activities had little to no initial perception of the dangers and consequences associated with tobacco product usage. The experiential learning activities and presentations conducted at the BGCA in Southeast Alabama provided the foundation for the students' perceptions of tobacco products, their dangers and tobacco serving as a gateway to using other substances. It is known that BGCA target at-risk adolescent populations which are more likely to have substance abuse disorders [2-5]. Knowing that the results from this research study provided a positive impact towards changing the adolescents' perception of tobacco related products, the risks associated with usage, and their beliefs of tobacco leading to other drugs or alcohol, practitioners would be wise to employ the Cone of Experience framework in the future.

Perhaps the most important information that can be gathered from the results of this research study indicates that students are less likely to partake in the use of tobacco products after experiencing educational learning activities. Tobacco usage has played a significant role in the declining health of the general population, ultimately paving the way for substance addictions later in life [4]. By educating adolescent populations living in an area prone to tobacco product usage, any positive change in their behaviors at an earlier age will improve their overall health and well-being for years to come. Therefore, practitioners should be encouraged to incorporate activities of this nature more frequently and abundantly. Additionally, educators within the public and private sectors should offer activities to assist with the reinforcement of such foundational knowledge to prevent tobacco usage.

\section{Limitations and Conclusion}

The major limitation of the study is the purposive, non-probability sampling method, since results cannot be generalized to the larger population. A probability sampling method would be beneficial to employ in future studies of similar nature. Another limitation is the age of the majority of respondents. The majority of respondents were reportedly nine years old, and although the researchers believe the educational seminar was beneficial for them to participate in, their comprehension of answering a survey may be too advanced. Future

JPHIP, an open access journal ISSN- 2581-7264 
studies should consider limiting the study to participants 11-12 years of age or older, as this was the intended target population due to this age demographic being more exposed and susceptible to peer pressures of experimenting with illegal substances such as tobacco, alcohol, or other drugs. It may also be of interest for this study to be replicated to address other health related issues impacting adolescents: sex education, alcohol awareness, marijuana or other drug usage, proper seatbelt usage, and texting while driving are a few topics to be considered.

There is valuable information to be derived from this study that could apply to various populations: educators, health care professionals, social workers, and child care workers to name a few. Educators and child care workers could benefit from this information as they are in direct contact and have significant influence on adolescent populations. Utilizing similar presentations and projects in classroom environments could assist in decreasing the likelihood of partaking in activities that are considered dangerous or risky. To help with the promotion of permanent learning, teachers should help students identify needs and set goals related to those needs. Using Dale's [6] Cone of Experience, these professionals can tailor the learning experiences to be meaningful and appropriate to the different developmental stages of the students. Health care professionals and social workers can employ similar program offerings to disperse information to their patients and clients to help reduce the probability of children and adolescents using in tobacco related products or participating in other risky behaviors and activities.

Throughout this research effort, it is evident that there is a need for effective educational presentations related to tobacco prevention and substance abuse for populations that are considered at-risk. Specifically, there is a need for special programs to be created for those living with intellectual disabilities and to develop health promotion activities to assist with positive change related to retention, perception, and behavioral choices [4]. Future research efforts could easily use this study as a foundation to address other areas of concern for adolescents for the betterment of their overall health and wellbeing.

Conflicts of interest/Competing interests: Authors report no conflict or competing interest.

\section{References}

1. Centers for Disease Control and Prevention. (2017). Learning Disorder.

2. Karacostas, D. D., \& Fisher, G. L. (1993). Chemical dependency in students with and without learning disabilities. Journal of Learning Disabilities, 26(7), 491-495. http://dx.doi.org/ Retrieved from

3. Beitchman, J. H., Wilson, B., Douglas, L., Young, A., \& Adlaf, E. (2001). Substance Use Disorders in Young Adults With and Without LD. Journal of Learning Disabilities, 34(4), 317-332.

4. Emerson, E., \& Turnbull, L. (2005). Self-reported smoking and alcohol use among adolescents with intellectual disabilities. Journal of Intellectual Disabilities, 9(1), 58-69. http://dx.doi. org/10.1177/1744629505049730

5. Molina, B., \& Pelham, W. E. (2001). Substance Use, Substance Abuse, and LD Among Adolescents with a Childhood History of ADHD. Journal of Learning Disabilities, 34(4), 333-342.

6. Dale, E. (1969). Audiovisual methods in teaching (3rd ed.). New York: Dryden Press.

7. Truth Initiative. (2019). Tobacco use in Alabama 2019.

8. Cheng, T. C., \& Lo, C. C. (2010). Mental Health Service and Drug Treatment Utilization: Adolescents with Substance Use/ Mental Disorders and Dual Diagnosis. Journal of Child \& Adolescent Substance Abuse, 19(5), 447-460. http://dx.doi.org/ 10.1080/1067828X.2010.515887

$\mathrm{J}$ Pub Health Issue Pract

Volume 4. 2020. 168
9. Katims, D. S., Zapata, J. T., \& Yin, Z. (1996). Risk factors for substance use by Mexican American youth with and without learning disabilities. Journal of Learning Disabilities, 29(2), 213-219.

10. Kepper, A., Monshouwer, K., Dorselear, S., \& Vollebergh, W. (2011). Substance use by adolescents in special education and residential youth care institutions. Euro Child Adolescent Psychiatry, 20, 311-319. http://dx.doi.org/10.1007/s00787-0110176-2

11. Maag, J. W., Irvin, D. M., Reid, R., \& Vasa, S. F. (1994). Prevalence and Predictors of Substance Use: A Comparison between Adolescents with and Without Learning Disabilities. Journal of Learning Disabilities, 27(4), 223-234.

12. Yu, J. W., Buka, S. L., Fitzmaurice, G. M., \& McCormick, M. C. (2006). Treatment Outcomes for Substance Abuse among Adolescents with Learning Disorders. Journal of Behavioral Health Services \& Research, 33(3), 275-286. http://dx.doi.org/ Retrieved from

13. University of Maryland Medical Center. (2017). Substance Use.

14. National Institute on Drug Abuse. (2014). Principles of Adolescent Substance Use Disorder Treatment: A ResearchBased Guide Introduction. Retrieved from https://www. drugabuse.gov/publications/principles-adolescent-substanceuse-disorder-treatment-research-based-guide/introduction

15. Lee, S. J., \& Reeves, T. C. (2007). Edgar Dale: A significant contributor to the field of educational technology. Educational Technology, 47(6), 56-59.

16. Bruner, J. S. (1966). Toward a theory of instruction, Cambridge, Mass.: Belkapp Press.

17. Anderson, H. M. (n.d.). Dale's Cone of Experience.

18. Cone of Experience. (2012). Retrieved from http://www. learning-theories.org/doku.php?id=instructional_design:cone of_experience

19. Steinberg, L., \& Monahan, K.C. (2007). Age differences in resistance to peer influence. Developmental Psychology, 43(6), 1531.

20. Roffman, J.G., Pagano, M. E., \& Hirsch, B. J. (2001). Youth functioning and experiences in inner-city after-school programs among age, gender, and race groups. Journal of Child and Family Studies, 10(1), 85-100. doi: 10.1023/A:1016681517546

21. Boys and Girls Club of America. (2019). Our Mission and Story.

22. Churchill Jr, G. A. (1979). A paradigm for developing better measures of marketing constructs. Journal of marketing research, 64-73.

23. National Institute on Drug Abuse. (2018). Teens Using Vaping Devices in Record Numbers. 